\title{
Medio siglo de asociacionismo americanista español 1885-1936
}

\author{
ISIDRO SEPÚlVEDA MUÑOZ*
}

En la segunda mitad del siglo xIX se produce en España el paulatino afianzamiento político y económico de la clase sustentadora del liberalismo. La «bisagra» política de la I República separa virtualmente el predominio de la oligarquía de base agraria y la nueva burguesía de moderno carácter capitalista, vinculada a la economía industrial y al comercio internacional; la plataforma operativa de esta nueva clase dirigente era el sistema la Restauración, cuya democracia aparente estaba basada en el dominio absoluto del sistema electoral.

Fue en este periodo y entre esta nueva clase, primero surgente y más tarde dirigente, donde comenzaron a producirse las primeras preocupaciones de la cada vez más débil metrópoli hacia las repúblicas americanas surgidas de sus antiguas colonias; además de desarrollar los principales proyectos de modernización económica y autonomía política de las que todavia se mantenian bajo dominio español; Cuba, Puerto Rico y Filipinas. Independiente de su labor política, su interés por los temas relacionados con América tuvo su manifestación más notable en la labor periodística, donde llegaron a editarse un buen número de revistas y diarios ${ }^{1}$.

Departamento de Historia Contemporánea, UNED.

- Revista Española de Ambos Mundos (1853-1855), La América (1857-1874 y 18791886), El Museo Universal (1857-1869), Revista Hispano-Americana (1864-1867), La llustración Española e Hispanoamericana (1870-1921), El Correo de España, (1870-1872), La Revista Hispanoamericana (1881-1891) o Los Dos Mundos (continuadora de La América y siguiendo el modelo de la revista francesa más acreditada de la época, La Revue des Deux Mondes). Un buen estudio sobre una de estas publicaciones y las vinculaciones entre la reciente burguesía comercial y el aumento del interés por América en LOPEZ OCON, L., Biografía de "La América": una crónica hispanoamericana del liberalismo democráctico español, Madrid, CSIC, 1987. 
El interés por un acercamiento entre España y las repúblicas americanas, además de tener su origen en la definición de la entidad nacional, tema que no se entrará a estudiar aquí, encontraba en la regularización de relaciones diplomáticas y comerciales un amplio campo de acción, apenas aprovechado. Ante la escasez de medios de la acción oficial y una política exterior que prestaba al continente americano poca atención, en los quince últimos años de siglo apareció el fenómeno del americanismo asociativo. La creación de asociaciones cuya vocación americana alcanzaba diferentes ámbitos respondía, además de los expuestos en sus estatutos, a fines e intereses muy diversos: económico-comerciales, diplomáticos, culturales, sociales, etc. Aunque éstos variaron con los sucesivos procesos políticos nacionales (Restauración, guerra y descolonización antillana, monarquía parlamentaria, dictadura primorriverista, / República, guerra civil) y las diversas coyunturas internacionales, hubo una clara continuidad en los planteamientos generales de estas asociaciones durante todo el periodo, siendo repetidas las llamadas a la unidad de acción e intentos gubernamentales de reunir los dispersos esfuerzos, en la pretensión de coordinándolos bajo directrices oficiales.

Esta fue, por otro lado, la etapa donde en mayor número y con mayor fuerza operaron las asociaciones americanistas. Tras la guerra civil y con el triunfo franquista se impuso una orientación en la política exterior hacia América fuertemente ideologizada, además de decretarse el monopolio de la acción oficial en este campo; lo que condujo a la desaparición de las asociaciones o a una continuidad mediatizada e inoperante. Con la transición hacia la democracia y la implantación de una monarquía parlamentaria apenas ha podido renacer el movimiento, debido a dos motivos: la continuidad, e incluso incremento, de la acción oficial (materializada en el Instituto de Cooperación Iberoamericano) y la desaparición del voluntarismo que impregnaba todos los programas de estas asociaciones, dado que los fines teóricos que perseguian estaban muy lejos de sus posibilidades. Los eventos a celebrarse en 1992 (los debates sobre su denominación - descubrimiento, encuentro, llegadadicen mucho respecto a la valoración y significado de lo conmemorado) por un lado han reforzado el oficialismo operativo en el diálogo EspañaAmérica, por otro han propiciado la aparición de algunas pequeñas asociaciones; el tiempo mostrará su carácter coyuntural o el verdadero deseo de trabajo a largo plazo.

Las páginas que siguen son un repaso somero de las principales asociaciones americanistas españolas durante el período 1885-1936, época dorada de dicho asociacionismo. 


\section{UNIÓN IBERO-AMERICANA ${ }^{2}$}

El creciente interés de círculos españoles por la actualidad americana y por el incremento de relaciones entre ambas entidades, manifestado en no pocas ocasiones con críticas a la acción oficial y reflejo de la preocupación de la realidad americana y sus casi inexistentes intercambios con España, se concretó a mediados de los años ochenta con la fundación de la asociación Unión Ibero-Americana (UIA). Este fue un caso destacado dentro del movimiento americanista español, pues constituyó la asociación que más larga vida pudo mantener, logrando mantener su existencia hasta el fin de la guerra civil.

Fue fundada oficialmente el 25 de enero de 1885 (la preparación de su creación se retrotrae a los últimos meses de 1883) por un grupo de personajes con una amplia diversidad de intereses; éstos estaban vinculados con el mundo de la prensa, el comercio transatlántico y la representación diplomática de varias repúblicas americanas. Su propiciador fue Jesús Pando y Valle, director de la revista Los Dos Mundos, fue también consultor de varias compañias de comercio transatlantico; su primer Presidente, el senador Mariano Cancio Villaamil, entre otros muchos cargos públicos había sido intendente en Cuba; su principal patrocinio financiero lo remitía el Marqués de Comillas, Presidente de la compañia naviera Transatlántica Española ${ }^{3}$; contaba además con la aquiescencia y apoyo del mismo Ministerio de Estado, en la figura de su titular, Segismundo Moret ${ }^{4}$.

El artículo primero de sus estatutos hacía una declaración de los fines de la asociación:

La Unión Ibero-Americana tiene por objeto estrechar las relaciones sociales, económicas, científicas, literarias y artísticas de España, Por-

2 SePulveda, I., Unión Ibero-Americana (1885-1937). Madrid, UNED, Memoria de licenciatura; próx. edit. AECI.

${ }^{3}$ Para la importancia de la compañía en la activación del comercio y el papel de éste en el interés americanista, véase CANCIO VILLAAMIL, M., La Transatlántica Española. Necesidades de desarrollar nuestras comunicaciones terrestres y maritimas. Madrid 1987. DE Cossio, M. La Compañia Transattántica. Cien años de vida sobre el mar. Madrid 1958.

${ }^{4}$ Su discurso en la sesión inaugural (22 de marzo de 1885) marcó una línea de intervención de la sociedad como órgano oficioso de la iniciativa oficial hacia América; véase Actas de la Junta General, Archivo del Ministerio de Asuntos Exteriores (AMAE), Manuscritos Leg. núm. 689. 
tugal y las naciones americanas, donde se habla el español y el portugués, y preparar la más estrecha unión comercial en el porvenir.

Originada en ámbitos modestos, el padrinaje de alguno de sus integrantes pronto hizo entrar a la UIA en los círculos políticos y económicos, con notable influencia y un sorprendente radio de acción ${ }^{5}$. A ésto ayudo la articulación de su proyecto americanista, sistematizado en la proposición de lo que con un deseo de concreción se llamó "Los doce Puntos"; eran los siguientes:

1. Reconocimiento mutuo de los títulos facultativos y científicos para el ejercicio de las profesiones en los distintos Estados de España, Portugal y América.

2. ${ }^{\circ}$ Posibilidad de suprimir las aduanas terrestres entre España y Portugal, sin perjuicio de la renta de ambas naciones.

3. Falta de tratados con las Repúblicas Americanas: gestiones que deben practicarse para celebrarlos.

4. Convenios postales: estudios que deben celebrarse para la más segura y económica comunicación de pliegos e impresos, entre España y las Naciones ibero-americanas.

5. Estudio de una anteproyecto de edificio para Exposición permanente de frutos naturales y productos de la industria de las Naciones ibero-americanas en Madrid y recursos para llevarlo a cabo.

6. ${ }^{\circ}$ Estudios para los medios de habilitar locales en las Repúblicas hispano-americanas y en Brasil, para la Exposición permanente de productos naturales y de las industrias pertenecientes a España y Portugal.

7. ${ }^{\circ}$ Tratados de propiedad literaria con las Naciones ibero-americanas: gestiones que deban practicarse para celebrarlos.

8. ${ }^{\circ}$ Posibilidad de una reorganización económica en Cuba y Puerto Rico, que permita el desarrollo de su riqueza, ya sea con tratados de comercio o sin ellos.

9. Condiciones de la instrucción que deberá adoptarse para formar el personal de administración en nuestras providencias ultramarinas.

${ }^{5}$ Mediante el establecimiento de centros correspondientes autónomos la UIA pronto tuvo representación y aportaciones de varias provincias españolas (las principales fueron Vizcaya, Burgos y Alicante); pero su influencia mayor llegó con la constitución de una cadena de centros a lo largo de toda América en los dos años siguientes a su creación en Madrid; para estos últimos véase La Unión Ibero-Americana en México. Compilación de Actas, Reglamentos, Bases y Constitución. México, s.e., 1886. 
10. Qué medios deben emplearse para españolizar las gentes de color en nuestras Antillas de Cuba y Puerto Rico.

11..$^{\circ}$ El progreso de los pueblos guarda relación con el desarrollo de sus servicios civiles, destinándose a todos los de este carácter en España, el $24 \%$ del total del presupuesto de ingresos; ¿qué medios podian adoptarse sin lastimar los demás servicios para aumentar los civiles?

12. Causas del atraso y decadencia de la administración municipal y medios de remediarla ${ }^{6}$.

La importancia de los Doce Puntos en la UIA radica en constituir de modo sintetizado todo un programa de actuaciones y campos a cubrir, además de ser el primer programa concreto que el americanismo español exponía, sólo superado tres décadas después por el presentado de la mano de Rafael Altamira. Dados los bajísimos presupuestos internos de la Unión y del no demasiado alto número de afiliados, este ambicioso programa permite señalar una de las caracteristicas comunes a todo el movimiento hispano-americanista: el voluntarismo que animaba a sus integrantes; lo que no significa que fueran desconocedores de sus propias posibilidades. Al contrario, conocía la limitación de sus realizaciones, pero la plasmación de la idea genérica del americanismo en un programa servía para determinar un campo que de otro modo escapaba facilmente de ámbito de concreción.

Tras la etapa inicial de organización y crecimiento, la UIA entra en una espiral de proyectos y actividades, principalmente con propósitos concretos y materiales en la búsqueda de resultados palpables. Un hecho abre esta etapa: la fusión de la UIA con la asociación Unión HispanoAmericana, de semejantes planteamientos y con fuerte intervención de cónsules americanos; una consecuencia directa fue el acercamiento por primera vez al poder, el presidente Linares Rivas como ministro de Fomento y de Estado.

En 1890 la UIA fue declarada "Sociedad de Fomento y Utilidad Pública", paso previo para la celebración del IV Centenario del Descubrimiento de América. Para su organización la UIA presentó un proyecto con puntos que compartían el verbalismo oficial, aunque también se encontraban proyectos positivos que en su plasmación habria hecho fructi-

\footnotetext{
${ }^{6}$ Actas de la Junta general, 18 de abril de 1885; AMAE M-697. Los temas fueron presentados por Pando y Valle, quien meses antes también había redactado los estatutos.
} 
ficar el centenario ${ }^{7}$. Durante esta década su revista llevó a cabo un seguimiento más riguroso de la economía; plasmación física de esta preocupación comercial sería la construcción del Instituto-Museo Iberoamericano en Madrid, proyecto frustado cuando se encontraba en un estado muy adelantado.

El crecimiento de las hostilidades y el desastre final del 98 consiguieron remover el fondo de la Unión, haciendo obligatoria una recomposición de las posturas adoptadas por la dirección de la UIA durante el conflicto, dando lugar a la aparición de nuevas facetas. La más importante de las cuales sería el componente combativo del que antes carecía, concretado en la señalización del «peligro yanki», que tuvo posteriormente sus consecuencias más destacadas a medio y largo plazo.

Tras la derrota militar y diplomática española del 98 , con el fracaso absoluto de las tesis mantenidas por la dirección UIA, se manifiesta la necesidad de cambio en las formas y en el fondo, potenciadas por un proceso de introspección y redefinición ideológica. El retorno a la secretaría general de Pando y Valle y la aparición del liberal Luis de Armiñán al frente de la revista dieron un nuevo y más reposado aire a la trayectoria de la asociación. Esta etapa comienza con la organización y celebración del Congreso Económico y Social de $1900^{\circ}$. En él se sentaron las bases de lo que fue el movimiento hispano-americanista, con importantes aportaciones de intelectuales, políticos y hombres de empresa españoles y americanos. La activa participación de éstos evidencia el cambio producido en la reclación con España.

Este período fue el más rico en cuanto a original plasmación literaria del pensamiento hispano-americanista (con todas las variantes que éste tiene), aprovechando el crecimiento del diálogo enriquecedor entre los intelectuales de las repúblicas americanas y de España, fruto de un movimiento de solidaridad que contrasta con el alejamiento anterior.

Esta etapa tiene como consecuente lógico la creación de la llamada —nada ocasionalmente- "Fiesta de la Raza», con la que el 12 de oc-

\footnotetext{
7 «Proyecto de programa redactado por la Junta Directiva de la Unión Ibero-Americana para la celebración del Centenario del descubrimiento de América", Unión Ibero-Americana, 1 de mayo de 1890, pág. 21 ss. Entre otras propuestas sobresalen la construcción de un Instituto Ibero-Americana (edificio multifuncional con bibliotecas, museo, exposición comercial, residencia e Iglesia) y la declaración del 12 de octubre como fiesta nacional en todas las naciones americanas y en España.

${ }^{8}$ Congreso Social y Económico Hispano-Americano. Actas; 2 vol. Madrid, Imp. Hijos de M. G. Hernández, 1902.
} 
tubre recibe una significación, siempre abierta a nuevas interpretaciones, cuyas resonancias llegan hasta la actualidad ${ }^{9}$.

Este enriquecimiento se vio completado con una mayor preocupación, pero menos envuelta en frágiles ropajes floridos, sobre la política internacional americana, principalmente de Centroamérica, donde se mostraba con su verdadero rostro - para quie no lo hiciera ya en 1898la agresiva política exterior de los USA. La argumentación "antiyanki» y la lucha contra el panamericanismo llenó muchas páginas y conferencias de la UIA. Este éxito de iniciativa no pudo ser digerido por la UIA; los diez años siguientes centró su actuación casi exclusivamente en la preparación y promoción de la Fiesta, olvidando la continuación de anteriores iniciativas.

Los cambios políticos que potenció la toma de poder de Primo de Rivera marcaron el camino para una reestructuración interna que dio lugar a reformas de consideración. Éstas comenzaron con el cambio de dirección, tras la fusión con la "Asociación Hispano-Americana"; produciéndose la paradoja por la que los recien ingresados tomaron la dirección en sus manos. La política de reactivación seguida por la presidencia del Duque de Alba, operativamente ayudado por el Secretario José Antonio Sangróniz, marcó un relanzamiento de la asociación, aunque tal hecho casi únicamente se produzca en su dimensión cultural, desapareciendo todo vestigio de seguimiento de la economía ${ }^{10}$. Caso contrario ocurre con la crónica política, que encontrará un amplio hueco en la nueva Revista de las Españas, y de igual modo podría decirse de la plasmación del pensamiento americanista, tanto en la revista como en

${ }^{9}$ Un exito de la UIA cuya repercusión espacio-temporal fue única: se extendió y fue acogida por todos los paises lberoamericanos, manteniéndose y recreándose hasta hoy. Brasil, Nicaragua, Costa Rica y Panamá ya celebraban el 12 de octubre con un carácter distinto, modificado a partir de entonces. Los países y años en que hicieron oficial la fiesta fueron: República Dominicana, 1912; Guatemala y Puerto Rico, 1913; Bolivia, Honduras y Paraguay, 1914; Ecuador, El Salvador y Uruguay, 1915; Argentina y Perú, 1917; España y Colombia, 1918; Chile y Venezuela, 1921; Cuba, 1922; y México, 1929.

10 Su manifestación externa se encuentra en la publicación de una más extensa y mejor presentada revista, en la edición de una serie de libros en la colección Revista de las Españas, en el envío de personalidades académicas a América en comisión de servicios, el sostenimiento del Patronato de Estudiantes Hispanoamericanos, el importante papel jugado en la Exposición Iberoamericana de Sevilla (por la que publicó el Libro de Oro Iberoameircano), en el enriquecimiento considerable de la Biblioteca Hispanoamericana (en 1930 alcanza los doce mil volúmenes), en la organización de importantes cursos de conferencias y en la reactivación de los centros correspondientes, principalmente en las distintas ciudades españolas. Simbólicamente, este crecimiento se sintetiza en la concesión gubernamental de la nueva sede social, antiguo "Palacio de Hielo". 
los cursos de conferencias. Este programa de reactivación, con algunas aportaciones originales pero principalmente rescatando campañas anteriores, tuvo como necesario apoyo económico las aportaciones del Estado por medio de los presupuestos generales y de la Junta de Relaciones Culturales.

La llegada de la República ocasionó a la Unión la apertura de una crísis de la que tardó en recuperarse. La causa más importante de esta crisis fue la creación en amplios sectores de la UIA de un conflicto de identidad del que en gran parte no llegó a recobrarse, dadas las abiertas simpatías hacia la monarquía de la mayoría de sus integrantes, comenzando por la dirección. Finalmente, la división ya manifiesta en el interior tuvo paralelismo trágicos a nivel nacional: la guerra civil acabó con la trayectoria vital de la UIA, ya que la creación del Consejo de la Hispanidad acayó todo intento no integrado al sistema triunfante ${ }^{11}$.

\section{CENTRO DE CULTURA HISPANO-AMERICANA}

Un tipo de americanismo de abierto carácter conservador lo constituye el Centro de Cultura Hispano-Americana, por más que su carácter social fuera muy semejante al anterior (incluso muchos de sus miembros pertenecian a la UIA). Su historia es monocorde y sin variaciones significativas, desde que el 27 de junio de 1910 fuera oficialmente fundado en sesión solemne presidida por el ministro de Instrucción Pública y Bellas Artes, Julio Burrell; su inspirador y animador principal fue Luis Palomo y Ruiz; quien presidió la asociación durante toda su existencia. Su posicionamiento político queda bien marcado al señalar que su principal valedor y protector fue José Canalejas, a quien incluso tras su asesinato siguió teniéndosele como elemento guía.

Los fines del Centro radicaban en un ambiguo acercamiento entre los países de habla castellana y una defensa de la cultura española. Este acercamiento nunca fue definido claramente, por más que en las páginas

1 Los presupuestos republicanos para 1937 aun consignaban una subvención para la UIA de 40.000 ptas.; AMAE, Leg. R-2136, exp. 2.-Su existencia quedó cortada por la Orden del Ministerio de Asuntos Exteriores de 30 de enero de 1941, BOE, 1 de febrero de 1941. Al mismo tiempo fueron expropiados su local, biblioteca, hemeroteca, archivo y demás pertenencias, otorgadas al recien creado Consejo de la Hispanidad; AMAE, Leg. R3538, exp. 2. 
de su revista fueran numerosos los trabajos reclamando una unificación de base política, económica o cultural. Su Vicepresidenta, Blanca de los Ríos, denominó el movimiento en que estaba integrada de «unificación étnica". Calificación que se ajustaba a la apreciación que desde su comienzo el Centro hizo de la comunidad ideomática, histórica y sociológica; en definitiva, y usando una de las acepciones más extremas del vocablo: una comunidad de raza ${ }^{12}$.

Más que en la constatación del presente o la definición de un proyecto de futuro, el programa de acercamiento de Cultura Hispano-Americana se concretaba en la recuperación de un pasado en el que, esgrimiendo constantemente la figura y la obra de Menéndez Pelayo -más un seguimiento de la historiografía estadounidense de signo similar: Willian $\mathrm{H}$. Prescott-, se trataba de reivindicar una historia únicamente atenta a demostrar las equivocaciones malintencionadas de la visión extranjera sobre el pasado español, especialmente del período colonial. Fue por tanto una labor que de modo prioritario estaba encaminada a combatir la leyenda negra, per en cuya contraargumentación no siempre reparó en recaer en las más extremas interpretaciones, tratando de reparar los agravios con exageraciones que en algunos casos sólo pueden ser calificadas de desatinadas ${ }^{13}$. Para potenciar la recuperación del pasado, sobre los que se cargaron los más glorioso tintes, el Centro acometió la tarea de reeditar los "más de 20.000 volúmenes de los tiempos heroicos $y$ de los descubrimientos" ${ }^{14}$; tarea que por la falta de los medios necesarios fue abandonada.

${ }^{12}$ "Donde espiritualmente conviva la raza que ni el Oceáno, ni la emancipación, ni influjo alguno, logrará separar, porque la unirán siempre la heredada sangre, las poderosas leyes fisionómicas y psíquicas de la herencia y la consaguinidad eterna del idioma, que no es un mero amontonamiento de vocablos, sino la esencia misma de la estirpe, una e indivisible como el alma que nos anima». DE Los RIOS, B., "Editorial»; Cultura HispanoAmericana, mayo de 1912, pág. 2.

13 La posición más radical de esta campaña la alcanzó a sistematizar Julio Cola; los enunciados de su argumentación puede concretarse asii; 1.-Todo por y para España; 2.-España ha colaborado más que todas las naciones juntas en el progreso de las ciencias y en el establecimiento de las instituciones juridicas, literarias, filosóficas y didácticas existentes); 3.- Ha sido la única nación defensora de los indios en América; 4.-Gastó en colonizar América tres veces más que lo que recaudó en ella; 5.-Todas las naciones aprendieron de España los madios y procedimientos de colonización, pero España no pudo aprender ninguno de ellos; 6.-El amor de España para las naciones americanas es semejante y su único deseo es una alianza espiritual con todos los pueblos de su origen. CoLA, J., Cultura Hispano-Americana, febrero de 1922, pág. 16.

14 Se pensaba utilizar los catálogos y guías de la Biblioteca Hispana de Nicolas Antonio (1680), la Biblioteca Occidentalis de Pinedo (1690), la Historia de la Conquista de Antonio Solís (1699), La Historia Natural y Moral de las Indias Occidentales (1590), el Memorial de Juan de Albarado (1626), el catálogo de la Sección americana de la Biblioteca Nacional, el catálogo de Jiménez de la Espada y las "papeletas bibliográficas" de Méndez Bejarano. 
Igual suerte corrió el ambicioso proyecto de la organización de un Congreso Cultural Hispanoamericano; presentado como una continuación del Congreso Económico y Social de 1900 en Madrid y el de Geografía de 1914 en Sevilla. Su celebración iba ligada desde su origen a la Exposición Iberoamericana que debía celebrarse en Sevilla tras el fin de la guerra mundial y fue periódicamente aplazada. Los trabajos de preparación del congreso, iniciados en 1917, a partir de 1918 consiguieron repetidas aprobaciones oficiales, pero no los apoyos económicos esperados por más que la nómina de personajes participantes en el proyecto fuera brillante» ${ }^{15}$.

Un proyecto del Centro que alcanzó a hacerse realidad fue la creación del "Liceo de América". El objetivo de esta nueva entidad jurídicamente independiente del anterior, era según sus propios estatutos «La alianza espiritual de España con todos los pueblos de su origen" ${ }^{16}$. De forma y contenido muy diferente al del patrocinador, el Liceo se inauguró el 5 de noviembre de 1919 (tenía previsto hacerse el 12 de octubre) en el antiguo palacio del duque de Nájera, en la ostentosa calle de Alcalá del Madrid de principios de siglo. Pretendiendo erigirse en una reunión superadora de Ateneo de Madrid y de la Unión Ibero-Americana (su teórica, ya que nunca llegaron a funcionar, división en secciones de trabajo estaba tomada de la UIA), derivó rápidamente hacia el campo lúdico, quedando los propósitos iniciales relegados a acontecimientos puntuales de escasa trascendencia.

\section{CASA DE AMÉRICA-INSTITUTO DE ECONOMÍA AMERICANA}

Las diferencias de entender el americanismo entre Madrid y Barcelona se pusieron en evidencia con la creación de la tercera gran asociación americanista, la Casa de América el 2 de abril de 1911. Aun manteniendo ciertos ecos del verbalismo de sus colegas castellanos, los propósitos de la Casa se mostraban muy en consonancia con los de sus integrantes, en su práctica totalidad ligados a los círculos económicos y

${ }^{15}$ Cultura Hispano-Americana, núm. 148-150, septiembre-diciembre de 1925, número monográfico y extraordinario dedicado a la recopilación de la labor realizada para la celebración del congreso.

${ }^{16}$ "Estatutos del Liceo de América", Cultura Hispano-Americana, 15 de marzo de 1919, pág. 7. 
mercantiles catalanes. No en vano la revista que fue tomada por tribuna (ya que no mantuvo un órgano de prensa propio) fue la revista Mercurio, cuya cabecera se completaba con el explícito subtítulo «Revista Comercial Ibero-Americana” ${ }^{17}$.

Fue un artículo de Rafael Vehils aparecido en la revista a finales de 1909 el que dio origen a la asociación barcelonesa. Lo que en él se proponía, y en primera instancia fue creado, era un centro de estudios de las repúblicas americanas que huía de todo rastreo del pasado para centrarse en la contemporaneidad más efectiva, especialmente en su dimensión económica. Con este fin se fundó la «Asociación de Estudios Americanistas" el primer día del año 1910; instalada en la Universidad Literaria, su gestión directiva estaba encomendada a americanistas tan ilustres como Labra, Altamira o Rahola (director de Mercurio) ${ }^{18}$. Paralelamente fue fundado por algunos integrantes de la colonia de americanos en Barcelona el llamado "Club Americano", con el propósito de reunir intereses de los residentes en la ciudad y ayudar a los transeúntes que desde el otro continente llegaban a ella. Ambas entidades funcionaron apenas algo más que sobre el papel, pues pronto surgió la idea de unir ambas iniciativas. Así nació la "Casa de América", operativa desde $1911^{19}$.

Entre sus actividades más destacadas cabe citar la organización de actos conmemorativos (en la larga lista de centenarios de independencias, aniversarios de hechos señalados, Fiesta de la Raza, etc.) y reuniones tendentes a la unificación del asociacionismo americanista español (Asamblea de Propaganda Americanista, Asamblea Nacional de Socie-

${ }^{17}$ Se ha venido dando por supuesto que Mercurio: Revista Comercial Ibero-Americana era el órgano de prensa de la Casa de América, de igual modo que las anteriores asociaciones tenian Unión Ibero-Americana y Cultura Hispano-Americana. Pero en este caso la adscripción se dio a la inversa; algunos participantes, en la labor de Mercurio decidieron dar a sus proyectos una plataforma jurídica, lo que les llevó a la fundación de la Casa. EI primer número de Mercurio apareció el 3 de diciembre de 1901, mientras que la Casa de América fue fundada diez años después.

${ }_{18}$ VeHILs, R., América en España. Estudios americanistas en Barcelona. Barcelona, s. e. [Casa de América], 1910.- Rahola había publicado unos años antes un interesante libro sobre su viaje a América, en el que de modo particular se preocupa de la cuestión social en las repúblicas americanas y la situación de los emigrantes españoles; temas que en Mercurio no tuvieron una especial presencia; RaHOLA, F., Sangre Nueva, impresiones de un viaje a América del Sud. Barcelona, Tip. "La Americana", 1905.

${ }^{19}$ La unión se consumó en noviembre de 1910; 2 de abril de 1911 se constituyó oficialmente. Su Junta directiva tenia como secretario general a Rafael Vehils y como presidente al uruguayo Jacinto Viñas; su Consejo de honor estaba formado por los cónsules generales de todas las repúblicas latinoamericanas, además de Estados Unidos. CARBONELL Tortos, F., Bodas de Oro de la Casa de América. Barcelona, s. e., 1961. 
dades y Corporaciones Americanistas, etc.) ${ }^{20}$. En 1912 la asociación por Real orden fue declarada de utilidad práctica por su fomento de «los estudios americanistas y las relaciones comerciales"; diez años después fue declarada de utilidad pública, nombrándola colaboradora del Consejo de Economía Nacional y miembro de la Junta Nacional del Comercio Español en Ultramar. En realidad la Casa funcionaba como un centro de estudio y conferencias, dividida su labor en cuatro comisiones: comercio, finanzas y comunicaciones; legislación comparada; previsión y trabajo; y comisión de estudios americanistas; todas ellas produjeron a lo largo de los años numerosas monografías, publicadas por la Casa. Su biblioteca, que a finales de los años diez alcanzaba los 10.000 volúmenes (libros y folletos), en 1929 poseía cerca de los 20.000; mantenía demás un extenso "Archivo general de economia", archivo documental con artículos periodísticos que en 1927 superaban las 80.000 entradas.

El carácter de la asociación quiso ser puesto de manifiesto en su propio nombre con motivo de la celebración de la Exposición Internacional de Barcelona en 1929; la Casa de América cambió su nombre por el de "Instituto de Economía Americana»; a la vez que con el cambio de estatutos se hacía profesión pública del corporativismo defendido durante la dictadura primorriverista. Su nuevo Director, Rafael Vehils, era además vocal del Consejo Superior de Cámaras de Comercio y la dirección de la Junta Nacional del Comercio Español en Ultramar estaba copada por integrantes del Instituto; cuando ésta dio lugar a la Dirección General de Comercio y Política Arancelaria (origen del posterior Ministerio de Comercio) su primer titular, Carlos Badia, y el secretario general, Eduardo Viada, eran hombres ya integrantes de la primitiva Casa de América. Este lanzamiento, que proyectó a hombres del Instituto a puestos de relevancia, no fue tan bueno para la marcha de la entidad, pues excepto el I Salón de Productos Americanos y Filipinos (1935) apenas se realizó actividad alguna que la permanencia del centro de estudios. La guerra civil y la guerra mundial dejaron éstos en suspenso; cuando tras 1945 se

${ }^{20}$ Memoria de la Asamblea de Propaganda Americanista. Mataró, s. e., 1911. Memoria de la Asamblea Española de Sociedades y Corporaciones Americanistas. Barcelona, Tip. "La Académica", 1911. Esta reunión, celebrada del 16 al 20 de diciembre, contó con una nutrida y significativa representación americana, incluyendo a los ex-presidentes de Colombia, Rafael Reyes, y de Nicaragua, José Santos Celeya. En ella se expuso a discusión un programa de actuación del americanismo español de seis puntos: 1.— - Intimidad iberoamericana"; 2.-Estudio de la emigración; 3.-Reforma de reglamentos y prácticas marítimas españolas; 4.-Unificación postal España-América; 5.-Incremento del comercio iberoamericano; 6.-Política cultural. Reglamento y cuestionario de la Asamblea Nacional de Sociedades y Corporaciones Americanistas. Barcelona, s. e., 1911. 
reanudó la actividad del Intituto habían desaparecido la mayoría de sus componenetes, llevando en adelante una existencia puramente testimonial.

La labor de la Casa de América-Instituto de Economía Americana fue principalmente la de suministrar información sobre las repúblicas americanas; tanto de sus fuentes de materias primas, condiciones industriales y de mercado, legislación económica y medios de transporte, como de usos y necesidades de las sociedades americanas y el modo de satisfacerlos y cubrirlos. Por tanto, el americanismo practicado por el núcleo catalán se manifestaba por medio del acercamiento económico y el intercambio comercial: «Las naciones de origen ibero vienen llamadas a constituir un poderoso núcleo, apto para nutrir un fecundo intercambio de productos" 21.

En esta dinámica la intervención de las potencias industriales (principalmente Estados Unidos, además de Gran Bretaña, Alemania y Francia) se contemplaba con una mezcla de incentivo y ejemplo a seguir por España, dentro de la participación en el reparto del mercado mundial, y como una política de recuperación del prestigio, cuando no clara influencia, en las sociedades americanas. Es en este intento de utilización de los lazos que histórica y culturalmente unian España y las repúblicas americanas donde se perciben con mayor claridad los propósitos y fines de la Casa ${ }^{22}$.

Mientras las anteriores asociaciones organizaron o respaldaron embajadas culturales a distintos países americanos, lo más destacado en tan sentido apoyado por la Casa fue el largo viaje de su secretario general Rafael Vehils en 1913 y 1914, visitando durante dieciséis meses Uruguay, Argentina, Paraguay y Brasil. En él estableció contacto con las cámaras de comercio y elaboró varios estudios de carácter comercial ${ }^{23}$.

${ }^{21}$ "Subsiste, en cambio, la afinidad de raza, la comunidad de idioma y la identidad de costumbres e ideas. No hay lazos que aventajen a éstos para impulsar y sostener una gran corriente mercantilı. Mercurio, 3 de diciembre de 1903, pág. 1.

${ }^{22}$ Fue significativo el apoyo que otorgó a la Unión-Americana desde el comienzo de su campaña para la celebración de la Fiesta de la Raza; y aún más lo fue la interpretación que la Casa hizo del festejo: "La fiesta de la raza no debe ser un puro sentimentalismo; tiene que equipararse a esas ferias donde se encuentran amigos y allegados para afianzar los afectos, sin olvidar un punto los negocios». RAHOLA, F., "Para la Casa de América, en la Fiesta de la Raza", Mercurio, 14 de octubre de 1915, pág. 2.

${ }^{23}$ Fruto de su viaje fueron una serie de memorias elaboradas por encargo de un grupo de entidades que apoyaron el periplo americano (Real Sociedad Geográfica, de Madrid y Barcelona; Asociación de Comerciantes Importadores y Exportadores, de Barcelona; Asociación de la Prensa, de Madrid y Barcelona; además del Centro de Cultura Hispano-Ameri- 
Fue por tanto el complemento a los periplos de carácter académico y cultural de Altamira y Posada" ${ }^{24}$.

\section{INTENTOS DE UNIFICACIÓN}

\section{Otras asociaciones americanistas}

La proliferación de este tipo de asociaciones, más otras que aún no siendo estrictamente americanistas por variadas razones tenían algún interés con respecto a América, hizo que en varias ocasiones se pretendieran unificar en una confederación; ya se han visto los intentos llevados a cabo por la UIA y la Casa de América. Éstos estaban condenados al fracaso por diversas razones, la más importante de las cuales era la falta de recursos para llevar adelante los programas presentados; fue por esto que en todos los intentos de unificación se pedia el apoyo oficial. Éste ya se otorgaba a las asociaciones anteriores y durante los años veinte se incrementó considerablemente ${ }^{25}$. Fue también en esta década cuando el Ministerio de Estado acogió la idea, fructificando en la segunda parte

cana y el centro de la Unión Ibero-Americana de Vizcaya) y la presentación de una serie de Apuntes sobre política arancelaria, política agraria y colonización, usos y costumbres mercantiles, infraestructuras industriales, etc. VEHILS, R., Los fundamentos del americanismo español y la misión oficial de la Casa de América en Argentina. Barcelona, E. Diaz, 1913. En su visita a las cámaras de comercio las invitó a la participación de una Conferencia Internacional Ibero-Americana, a celebrar en 1914; su programa, en gran parte, acabó siendo celebrado en 1929: Memoria de la Conferencia de Cámaras de Comercio y Asociaciones Americanas de comercio; convocada por el Instituto de Economía Americana y celebrada en Barcelona del 21 al 26 de octubre de 1929. Barcelona, s. e., 1930.

${ }^{24}$ Altamira, R., Mi viaje a América. Madrid, Lib. General de Victoriano Suárez, 1911. Gonzalez Posada, A., En América, una campaña. Madrid, s. e., 1911.

${ }_{25}$ La cuantia y procedencia de las ayudas económicas a las asociaciones varió de una a otra. La Unión Ibero-Americana dirigia sus memorias anuales al Ministerio de Estado, del que recibía una ayuda de 30.000 pesetas desde 1902, ampliada a 50.000 en 1927 . Cultura Hispano-Americana las dirigía al Ministerio de Instrucción Pública y Bellas Artes. Igual dirección tenían las de la Casa de América, hasta que en 1928 cambió de denominación y recibió ayuda del Ministerio de Estado. Además de estas entidades también recibian subvención de Instrucción Pública el Instituto Ibero-Americano de Derecho Comparado (12.500), el Centro Ibero-Americano de Cultura Popular Femenina (5.000) y la Junta de Fomento de las Reclaciones Artisticas y Literarias Hispano-Americanas (5.000); del Ministerio de Estado las recibia el Centro Internacional de Investigaciones Históricas Americanas (20.000). 
de la dictadura de Primo de Rivera un intento de unificación oficial que pretendía utilizar la labor de la asociaciones como complemento a la llevada a cabo por el Ministerio de Estado ${ }^{26}$.

Una primera aplicación de esta idea, con la sustancial modificación relativa a las subvenciones, ya fue utilizada en el proyecto de creación de un registro de asociaciones, casinos, sociedades y entidades de todo tipo que con carácter español existieran en América. Para su realización se contaba con la ayuda de los diplomáticos y cónsules en cada uno de los paises.

Aunque disfrutó de la simpatía inicial de la parte de la colonia que periódicamente pedia alguna medida en ese sentido ${ }^{27}$, una intromisión por parte de la dictadura en los asuntos propios de estas entidades no fue muy bien vista por buena parte de ellas, contrarias al dirigismo imperante en la Península. Mucho menos viniendo de un gobierno al que ya en esos momentos se comenzaba a enjuiciar severamente. Conocedor de esto, la misma orden que solicitaba el registro aseguraba que la apertura de éste no implicaba la "merma de la autonomía de tales Asociaciones, ni menos emancipación de las obligaciones que los ligan a la soberanía de los países en que radican". Por el contrario, se declaraba como el medio más efectivo para la realización de un censo "cuantitativa y cualitativo" de los emigrantes allí establecidos; mismo censo que desde finales del siglo XIX se venía realizando y nunca, como ahora, fue llevado a término ${ }^{28}$.

La apertura del registro se llevó a efecto, pero la lógica tardanza para la recogida de la información y su posterior estudio sumaron demasiado tiempo para la corta existencia de la Sección de América y Relaciones Culturales. Debido a un traspaso de funciones entre secciones tras

${ }^{26}$ La idea se había concretado en un memorándum preparado por el diplomático José Antonio Sangróniz (luego Secretario general de UHA y tras la unificación de la UIA), presentado al Ministerio de Estado meses antes del golpe de Primo de Rivera. Posteriormente, cuando se preparaba el retorno de Estado a su condición de ministerial, Sangróniz, con otros miembros de la UIA y del Centro de Estudios Históricos, tratan de sacar adelante el proyecto unionista, por lo que se editará su obra en forma de libro; SANGRONIZ, J. A., Proyecto de expansión cultural. Madrid 1923; AMAE, Leg. R-726 exp. 40. La expansión cultural de España en el extranjero y principalmente en Hispano-América. Madrid, Hércules, 1925.

27 Ortiz y San Pelayo, Félix, Boceto histórico de la Asociación Patriótica Española: desde su fundación hasta la reunión del Congreso de Sociedades Españolas. Buenos Aires, Libreria "La Facultad", 1914. "La segunda convención de los españoles en Méjico", Información Española, 1 de enero de 1928, págs. 35-37. “El presidente de la Cultural HispanoCubana en Madrid", lbidem, 15 de noviembre de 1928, págs. 1.023-1.024.

${ }^{28}$ Real Orden de 9 de marzo; Gaceta, 12 de marzo de 1927. 
la absorción de Estado por Presidencia de Gobierno o a un traslado de los funcionarios encargados de su elaboración, dicho registro fue finalmente realizado por la Junta Nacional de Comercio Español en Ultramar, dependiente del Ministerio de Trabajo, Comercio e Industria. A pesar de la labor llevada a cabo y la voluminosa documentación reunida ${ }^{29}$, nada se hizo con dicho registro, dejándose en el aire las espectativas creadas en buena parte de las entidades encuestadas.

Posterior a la apertura de este registro - aunque en ningún caso se tomó como precedente- el Ministerio de Estado decidió tomar la dirección efectiva del movimiento americanista español. El medio para llevar a cabo tal propósito fue la apertura, en la Sección de América y Relaciones Culturales, de un registro de "Asociaciones, entidades, centros, sociedades españolas, constituidas legalmente, que tengan como fin, en cualquiera de sus aspectos, el mantenimiento y estrechamiento de las relaciones con los paises hispano-americanos". La Real orden por la que se abría el registro declaraba puntualmente que el objeto final de la iniciativa era "unificar la acción" de dichas entidades, "consiguiendo en una obra de conjunto una eficacia que no se lograría quedando aquellos [esfuerzos] diseminados y dispersos" ${ }^{30}$.

Era por tanto evidente que dicha iniciativa constituía un primer paso para la creación de una gran entidad americanista, calco de la federación de asociaciones que se venía propugnando desde principios de siglo. Ahora no sólo apoyada desde instancias oficiales (como lo habían sido distintas asociaciones por varios ministerios), sin creada, fomentada y dirigida por el gobierno como una instancia ministerial más.

La misma ley marcaba el plazo de un mes para la realización del registro, aunque no explicitaba que ocurriria a las asociaciones que no se hubiesen inscrito. Lo cierto fue que el registro permaneció abierto al menos entre el 13 de julio y el 21 de octubre de 1927. La ampliación del

\footnotetext{
29 Esta documentación, conservada en frágil papel de copia, permanece inédita en el Archivo del Ministerio de Asuntos Exteriores, esperando un tratamiento relacional que analice la verdadera presencia asociativa española en América durante el primer tercio de siglo. AMAE R-533 Exp. 25.

${ }^{30}$ Real Orden de 25 de junio; Gaceta, 26 de junio de 1927. Aunque más crudamente, Sangróniz lo había expresado mejor, cunado para probar la necesidad de la ayuda oficial la condicionó al đirigismo del patrocinador: "Sería necesario para el bien del servicio nacional, una fiscalización de la labor realizada por estas entidades sobre las que el Estado, a cambio de la ayuda económica concedida, debe ejercer una misión tutelar. [Señalándoles] las líneas generales de su actuación para que marchen todas ellas de acuerdo con un programa definido, en forma que respondan a finalidades de positivo patriotismo". SANGRONiz, J. A., La expansión... Op. cit., pág. 88.
} 
margen debió ser consecuencia del escaso entusiasmo que tal iniciativa recibió de la mayoría de las asociaciones a que iba dirigida, ya que en más de tres meses únicamente 13 entidades pidieron su inserción, alguna de ellas de unos fines muy diferentes a los indicados. Estas entidades, con su fecha de creación y una breve descripción - puramente descriptiva-, fueron:

- "La Ginebrina", Almeria (Ginebra, 1877): cadena internacional de hoteles con un extraño asociacionismo entre sus empleados; abundancia de simbología masónica en su publicación mensual.

- «Unión Ibero-Americana" (Madrid, 1885).

- «Instituto Ibero-Americanano de Derecho Comparado" (Madrid, 1909): importante asociación de la abogacía "exclusivamente científica, docente y propagandista" ${ }^{31}$; su principal campaña americanista se dio en favor de una unificación de la legislación en todos los paises hispanohablantes. La presidencia en el momento de pedir la inscripción en el Registro la detentaba Rafael Altamira, siendo secretario general Manuel Azaña.

- “Instituto de Economía Americana», Casa de América (Barcelona, 1911).

- «Bolsa de Trabajo Internacional» (Madrid, 1919): asociación de emigrantes con confusa ideología socializante; con los años ésta se definió y durante la Dictadura gozó de cierta preponderancia por su defensa del estado corporativo.

- "Acción Católica; Confederación Femenina Hispano-Americana" (Madrid, 1919): a pesar de ser presentadas como dos entidades independientes, en realidad respondían a los mismos planteamientos y eran dirigidas por las mismas instancias; en la documentación aparece un amplio memorándum para su expansión en América.

- "Juventud Hispanoamericana» (1919): fue la asociación de estudiantes americanos residentes en España y reunió durante los primeros veinte a personalidades relevantes años después en sus países; posteriormente daría lugar a la Federación Universitaria Hispanoamericana y al

${ }^{31}$ Estatutos del Instituto Ibero-Americano de Derecho Comparado, 2. a Ed., Madrid, Salvador Cuesta, 1927. 
Patronato de Estudiantes Hispanoamericanos, éste creado dentro de la misma UIA.

- "Casa de América-Galicia» (La Coruña, 1920): creada como un centro correspondiente de la central barcelonesa, con posterioridad creció de modo independiente. Sus trabajos estaban dirigidos hacia el tema de la emigración y la coordinación - nunca lograda- de las colonias gallegas en América.

- «Junta Nacional de Comercio Español de Ultramar" (Madrid, 1923): entidad oficial creada por el Ministerio de Trabajo para la preparación y posterior puesta en práctica del Congreso Nacional de Comercio Exterior y de Ultramar.

- «Asociación Española de Ultramar» (Madrid, marzo de 1927): entidad nacida al calor oficial, teórica coordinadora de la futura confederación de asociaciones españolas en América.

Además de las registradas oficialmente - con desconocido criterio de selección-, existe en los mismos expedientes documentación de estas otras asociaciones: Unión General Hispano-Americana, Sindicato de Exportadores de Vinos, Instituto Hispano-Americano de Relaciones Culturales, Sociedad Hijos del Ayuntamiento de la Estrada, Sociedad de Instrucción y Beneficencia "Vivieso y su comarca» y Comité Hispano Filipino ${ }^{32}$.

Independientemente y en fecha no determinada, la Junta Nacional de Comercio Español de Ultramar había creado su propio fichero del americanismo asociativo español. Comparado con el anterior su seguimiento fue más extenso, pero no se ha encontrado documentación sobre la intensidad del conocimiento que del movimiento americanista tuviera en el Ministerio de Trabajo, Comercio e Industria. Bajo el título de «Entidades Hispano-americanistas", esta lista contenía únicamente el nombre de la asociación y su dirección postal. Estas entidades eran:

- Madrid: Junta Nacional del Comercio Español en Ultramar, Unión lbero Americana, Comité Ejecutivo del Palacio de América, Asociación de Españoles de Ultramar, Juventud Hispano Americana, Sociedad de Historia Hispano Americana, Centro de Cultura Hispano Americano, Centro Ibero Americano de Cultura Popular Femenina.

\footnotetext{
32 AMAE: Leg. R-516 Exp. 43 y Leg. R-533 Exp. 28.
} 
- Barcelona: Casa de América (Instituto de Economía Americana), Círculo de la Unión Mercantil Hispano-Americana, Unión General Hispano Americana.

- Bilbao: Centro de la Unión Ibero Americana de Vizcaya.

- Sevilla: Instituto de Estudios Americanistas.

- Cádiz: Real Academia Hispano Americana de Ciencias y Artes.

- Santander: Casa de América de Santander.

- La Coruña: Casa de América en Galicia.

- Huelva: Real Sociedad Columbina Onubense.

- Palos de Moguer: Club Palósfilo.

- Valladolid: Centro de Estudios Americanistas.

Al igual que otras iniciativas americanistas de la etapa de Primo de Rivera, este proyecto de creación de una gran entidad oficial coordinadora y directora del americanismo español fue abandonado sin ningún tipo de explicación. Hasta cierto punto fue subsumido por la labor de la Junta de Relaciones Culturales, aunque sólo como una sección más de su amplia ajecutoria y no la más importante.

Pero la idea inicial no dejó de ejercer atracción sobre los directores de la política exterior española. Durante la República y por iniciativa de algunos de los hombres que durante la Dictadura habian presentado el proyecto anterior, o habían tenido algún contacto con él, se realizaron varios proyectos que contemplaban la penetración de la presencia española en América. Uno de estos proyectos diseñaba la creación de un organismo oficial de carácter análogo al anteriormente perseguido, teniendo como base la infraestructura de la UIA ${ }^{33}$.

No fue hasta la finalización de la guerra civil (por más que ambos bandos utilizaran todos los medios a su alcance para recibir las simpatías, apoyos y ayudas de los países americanos) y el inicio de la conformación del nuevo régimen franquista cuando fue retomado el proyecto

${ }_{33}$ Plan de política de España en América. Madrid, 4 de diciembre de 1933. AMAE: Leg. R-973 Exp. 33. 
de creación de una entidad americanista oficial. Alcanzó realización efectiva con la constitutución del "Consejo de la Hispanidad" ${ }^{34}$, primero de una serie de organismos que han sucedido en el mismo campo hasta la fecha.

${ }^{34}$ Serrano Suñer fue quien creó y organizó el Consejo de la Hispanidad (BOE, 8 de enero de 1941), ayudado por el primer Cancilier del Consejo, Manuel Halcón. Olvidando el procedimiento de confederación, se pasó a ordenar por decreto la desaparición de aquellas entidades privadas con fines análogos a los desempañados por el Consejo ( $B O E, 1$ de febrero de 1941), e incluso a la incautación de su patrimonio, como ocurrió con el local, biblioteca y hemeroteca de la Unión Ibero-Americana, en Beneficio del Consejo. Para la utilización del Consejo de la Hispanidad en la política española en América ver la obra de Delgado, L., Diplomácia franquista y política cultural hacia lberoamérica, (1939-1953). Madrid, CSIC, 1988. BaRBEITo, M., El Consejo de la Hispanidad. Madrid, UNED, Memoria de Licenciatura, inédita. 